\title{
EXPANSÃO E QUALIDADE DA EDUCAÇÃO BÁSICA NO BRASIL
}

\author{
PAULO SÉRGIO MARCHELLI \\ Professor adjunto do Departamento de Educação da Universidade Federal \\ de Sergipe - Itabaiana \\ paulomarchelli@hotmail.com
}

\begin{abstract}
RESUMO
O trabalho consiste em uma apreciação crítica sobre a taxa de escolarização bruta, fluxo escolar, desempenho do estudante, evasão, repetência e outros indicadores utilizados como parâmetros para a avaliação da qualidade na educação básica brasileira. Trata-se de matéria de caráter ensaístico sobre o fato de que o custo de universalizar as matrículas foi uma perceptível queda no rendimento dos alunos. No entanto, o trabalho mostra que a qualidade deve ser considerada em termos representados pelos ganhos sociais da universalização do ensino e não unicamente pelas notas obtidas nas provas. São expostos problemas conceituais referentes ao novo Índice de Desenvolvimento da Educaçãa Básica, utilizado na formulação de políticas públicas para que o Brasil melhore sua posição no ranking internacional da educação.

AVALIAÇÃO DA EDUCAÇÃO - POLITICAS EDUCACIONAIS - QUALIDADE DO ENSINO DADOS ESTATÍSTICOS
\end{abstract}

\begin{abstract}
EXPANSION AND QUALITY OF PRIMARY AND SECONDARY EDUCATION IN BRAZIL. This paper is a critical appreciation of the overall schooling rate, school flow, student performance, truancy, repeat years and other indicators used as parameters for assessing the quality of Brazilian education. This is essay material about the fact that the cost of making school enrollment universal led to a perceptible drop in student performance. Nevertheless, the work shows that quality must be considered in terms that are represented by the social gains achieved as a result of the universilization of education and not only from the marks obtained in tests. Conceptual problems are revealed, such as those relating to the new Basic Education Development Index (primary and secondary education), which is used in Brazil for formulating public policies in order to improve its position in the international education ranking.

CURSE EVALUATION - EDUCATIONAL POLICIES - TEACHING QUALITY - STATISTICAL DATA
\end{abstract}


A ideia inicial de avaliação da qualidade em educação efetuada por agentes externos à escola parecia inverter os valores humanistas do discurso pedagógico e sobre ela foram lançadas críticas severas, que a acusaram de ser politicamente incorreta, desumanizadora e tributária dos exageros advindos pela paixão ao planejamento que hoje alimenta a agenda neoliberal das sociedades pós-industriais. Gentili (1997, p. I I 5) lembra que: "O discurso da qualidade referente ao campo educacional começou a desenvolver-se em fins da década de 80 como contraface do discurso da democratização". Em Macedo (2006, p. 46) encontra-se que: "A globalização associada ao discurso neoliberal tem nos colocado diante da ideologia da eficiência e da qualidade técnica como se não houvesse outras formas de ver o mundo".

Desde os anos 1990, como decorrência da universalização do ensino fundamental que se realizou no Brasil, a escola se viu envolvida com a responsabilidade de promover a aprendizagem de todos os alunos, independentemente da origem social e das condições culturais ou financeiras das famílias, legalmente obrigadas a matricular os filhos. Para tanto, foi preciso treinar os professores, facilitar o acesso do aluno aos livros didáticos, criar parâmetros curriculares, implantar ciclos de progressão continuada e, principalmente, inserir a avaliação externa. Essa e o credenciamento passaram a ser políticas de primeira ordem, conduzidas pela filosofia do controle da qualidade como forma de gerar competências, rendidas pelo argumento do custo-benefício da escola, pelo accountability ou prestação de contas à sociedade, pela necessidade de controle dos dados de repetência, evasão, exclusão etc. A permanência do aluno dentro do sistema escolar passou a ser considerada em si mesma uma vitória e a educação, além de direito básico começou a ser entendida também como uma prestação de serviços pelo Estado à população. Daí tem-se que:

.... conceito de avaliação que emergiu privilegiou a avaliação externa em todos os níveis de ensino, sob a lógica da competitividade entre as organizações ou entre os professores, em que a qualidade era produto da própria competição pela construção de uma coleção de indicadores legitimados socialmente pelos atores. (Freitas, 2004, p. 149)

A avaliação externa dos sistemas de ensino foi assim adotada pelos governos como um instrumento de controle político do desenvolvimento social. 
Os resultados dos exames aplicados aos estudantes passaram a ocupar um lugar central na agenda do planejamento educacional, considerados a forma de melhor eficácia para aferir a qualidade. Entendeu-se que os resultados da aprendizagem dizem respeito ao sistema escolar como um todo, que engloba a infraestrutura, meios de financiamento, organização do trabalho dos professores, administração de recursos pedagógicos, envolvimento dos pais e da comunidade, entre outros aspectos que podem ser destacados.

No final dos anos de 1990, a Organização para Cooperação e Desenvolvimento Econômico - OCDE - financiou o Programme for International Student Assessment - Pisa. Sua principal finalidade era realizar uma comparação entre países signatários sobre a efetividade dos seus sistemas de ensino, voltando-se para o desempenho de alunos na faixa dos I 5 anos, idade em que se pressupõe o término da escolaridade fundamental. Dessa forma, os exames externos de avaliação dos estudantes constituem atualmente uma prática consolidada, que pressupõe o uso das informações obtidas para a formulação de políticas públicas de planejamento educacional.

\section{DIMENSÕES, INDICADORES E ÍNDICES DE AVALIAÇÃO DA QUALIDADE EM EDUCAÇÃO}

universo linguístico do campo da avaliação educacional contém um vocabulário que somente foi estabelecido nos últimos anos, de forma a compor uma estrutura que embasa os múltiplos significados das operações necessárias para a elaboração de sistemas concretos. No universo avaliativo, as palavras vão surgindo de forma tempestiva cada vez que é necessário atribuir significados às novas práticas adotadas. Análises pautadas em diversas interpretações paralelas conduzem a uma ampla profusão de significações, pois não há uma linguagem uniforme para tratar das práticas avaliativas. Regras funcionais de linguagem são sistematicamente construídas, tendo em vista o funcionamento de um sistema amplo, mas pouco estruturado e pautado em semânticas que diluem o discurso pedagógico tradicional. Assim, a comunidade dos atores sociais responsáveis pela execução das avaliações se comunica através de uma sintaxe que se recusa a deixar de ser prolixa.

No Brasil, o consenso sobre qual sistema de avaliação deve ser utilizado tem força de Lei, havendo o Estado produzido distintos regulamentos para a 
Educação Superior (Brasil, 1996, 200 I , 2004, 2004a) e para a educação básica (Brasil, 2005). Uma ampla literatura de apoio técnico vem a seguir, também produzida pelo aparelho estatal para subsidiar a implantação dos instrumentos legais vigentes (Brasil, 1985, 2003, 2004, 2005). No campo acadêmico, muitos trabalhos foram produzidos, não sendo difícil selecionar bons autores que já escreveram e ainda escrevem sobre o assunto. Na área da Educação Superior, um dos mais citados é Dias Sobrinho (2003, 2002, 2000), destacando-se ainda Gonçalves Filho (2004), Gomes (2002), Ristoff e Davok (2000) e Vianna ( 1999). Ainda no âmbito da Educação Superior, o trabalho de Dias, Marchelli e Horiguela (2006) apresenta uma crítica histórica aos significados que permearam os procedimentos avaliativos brasileiros desde suas primeiras elaborações na década de 1980, partindo da análise das políticas produzidas pelo Estado. No domínio da pós-graduação pode ser citado o trabalho de Moreira, Hortale e Hartz (2004). Na esfera da educação básica, assunto para o qual este trabalho está voltado, destacam-se Ferrão, Beltrão e Santos (2007), Gomes (2005), Oliveira e Araújo (2005), Neves e Boruchovitch (2004), Jacomini (2004), Freitas (2002), Barretto et al. (200 I) e Franco (200 I).

Mesmo diante dessa grande quantidade de materiais de natureza legislativa e bibliográfica existente no campo da avaliação educacional, a produção de conteúdos simbólicos ainda é sofrível entre nós. Esse campo é determinado por um universo no qual estão inseridos os diversos agentes que produzem os sistemas de avaliação. Ao aplicar esses sistemas e analisar seus resultados, tais agentes estabelecem um universo caracterizado por linguagens e domínios técnicos que em muitos casos carecem de maior explicitação. Conforme Bourdieu (2003), no interior de todos os campos das ciências, artes e humanidades, ocorrem lutas simbólicas que os agentes sociais travam pela apropriação de bens e, consequentemente, pelo monopólio de competência e poder cultural. $\mathrm{Na}$ arena em que dão as lutas, grupos antagônicos disputam verbas de incentivo à pesquisa, indivíduos concorrem pelos mesmos cargos acadêmicos, corporações diversas são formadas tendo em vista a manutenção de vantagens e posições, bem como a disputa de privilégios materiais e simbólicos.

As relações objetivas entre os diferentes agentes que se posicionam dentro do campo da avaliação estabelecem o que pode e o que não pode ser feito, determinam os objetos a serem considerados, os meios de divulgação do seu trabalho, os locais de publicação etc. Cada agente detém uma espécie 
particular de capital simbólico, que se manifesta no reconhecimento concedido pelos pares. Conforme a importância desse capital simbólico, o mesmo agente indica, por intermédio de estruturas de conservação ou de subversão, o conjunto dos significados que se incorporam à linguagem do campo da avaliação. No Brasil, o detentor da maior parte do capital simbólico no campo da avaliação educacional é sem dúvida o Estado, seguido por organismos especializados de natureza pública, privada ou mista, havendo ainda participação de pesquisadores concentrados nas Instituições de Ensino Superior - IES.

Diante de tantas referências produzidas pelos agentes que se altercam no campo da avaliação educacional no Brasil, torna-se difícil selecionar o trabalho mais influente. Mas se isso tiver que ser feito, é razoável procurá-lo na literatura de apoio técnico gerada pelo Estado para subsidiar a implantação dos instrumentos legais vigentes. Feito isso, o trabalho eleito é o que explicita as diretrizes para avaliação externa das IES (Brasil, 2005a), constituindo do ponto de vista do autor desse artigo o documento que melhor contribuiu para o estabelecimento da linguagem no campo avaliativo no Brasil. Como literatura produzida pelo Estado, trata-se de uma obra que tem força normativa no que tange ao propósito de servir como parâmetro básico para orientar as atividades dos responsáveis pelos processos de avaliação legalmente instituídos, apresentando referências para a apreensão da qualidade das instituições de educação superior, sejam elas universidades, centros universitários ou faculdades, de caráter público ou privado. $\bigcirc$ documento define a matriz orientadora do processo de avaliação do ensino superior brasileiro com base nos significados de dimensão, indicador e índice.

A dimensão da avaliação é caracterizada pelos "grandes traços ou características referentes aos aspectos institucionais sobre os quais se emite juízo de valor e que, em seu conjunto, expressam a totalidade da instituição", enquanto o indicador diz respeito a "algum aspecto ou característica da realidade que se pretende avaliar” (Brasil, 2005a, p. 37). A dimensão constitui uma generalização ampliada que engloba as partes substanciais do sistema, enquanto o indicador exprime uma particularidade dentro daquela dimensão. Nos sistemas educacionais, normalmente duas espécies de dimensões são avaliadas: a aprendizagem, que diz respeito à agregação de conhecimento pelo aluno, sendo essa a finalidade precípua do sistema; e a escola, que diz respeito aos meios que o Estado utiliza para realizar aquela finalidade. Quanto aos índices, 
mesmo que o documento do Ministério da Educação citado não os defina de maneira explícita, ele os usa sistematicamente sob a forma da atribuição de conceitos numéricos na escala de I a 5, conforme prevê a legislação. Dessa forma, o índice trata de uma expressão numérica do indicador dentro de uma escala de comparação pré-definida.

A construção de uma matriz formada a partir da trilogia conceitual dada pelos conceitos de dimensão, indicador e índice tornou factível a ação prática dos agentes responsáveis pela avaliação das instituições brasileiras de ensino em geral. A partir da edição do documento acima citado, esses três significantes passaram a constituir a base da linguagem que todos os agentes responsáveis pelas práticas avaliativas passaram a adotar, de forma que ela está também presente de forma basilar na formulação do sistema de avaliação concebido no Brasil para a educação básica.

\section{O SISTEMA DE AVALIAÇÃO DA EDUCAÇÃO BÁSICA}

Dadas as circunstâncias de produção de conceitos explicitadas na seção anterior, desde o início dos anos de 1990 o Brasil tem conseguido avançar lentamente, mas de forma determinada em direção à criação de sistemas específicos para avaliação da educação. A Portaria 93।/2005 do Ministério da Educação (Brasil, 2005a) reestruturou o Sistema de Avaliação da Educação Básica - Saeb -, que existe desde 1990, quando foram aplicadas provas de português e matemática a uma amostra de alunos da $4^{\mathrm{a}}$ e $8^{\mathrm{a}}$ séries do ensino fundamental e da $3^{a}$ série do ensino médio.

A divulgação da série histórica de dados coletados pelo Saeb no período de 1995 a 2005 (Brasil, 2007b) ecoou como um grito de desespero, pois mostrou que a escola básica brasileira está percorrendo uma perigosa curva descendente de aprendizagem, acumulando déficits ano após ano e sugerindo a falência das políticas públicas formuladas pelo governo anterior e o atual. Com base nos dados divulgados, é possível ter uma ideia desse déficit por meio das diferenças entre as médias de uma edição para outra da prova. Assim, dentro da escala de medidas adotada que varia de zero a 500 pontos, as diferenças absolutas entre as médias bianuais comportaram-se para Língua Portuguesa segundo os valores mostrados no gráfico I. Considera-se o valor zero para a ordenada correspondente a 1995, início do período de avaliação. 
GRÁFICO I

VARIAÇÃO DAS DIFERENÇAS ENTRE AS MÉDIAS DE PROFICIÊNCIA EM LÍNGUA PORTUGUESA NA SÉRIE HISTÓRIA DO SAEB (1995-2005)

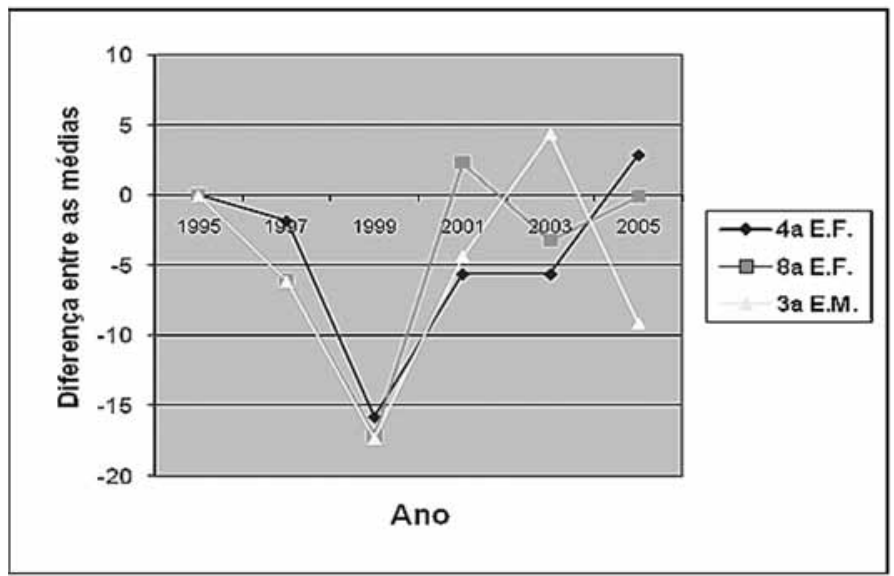

Fonte: Brasil (2007b, p. 6).

No gráfico, as diferenças entre as médias de uma edição para outra do Saeb estão situadas prioritariamente dentro do plano das ordenadas negativas, indicando que a educação básica brasileira não está conseguindo se recuperar de um acúmulo cada vez maior de déficits de aprendizagem. $O$ valor médio dessas diferenças em Língua Portuguesa para a $4^{\text {a }}$ série do ensino fundamental foi de -5, 18; para a $8^{a}$ série foi de -4,84; e para a $3^{\text {a }}$ série do nível médio foi de $-6,48$. Considerando que esses valores quantificam o déficit relativamente à escala de 500 pontos em que se distribuem as notas, no período considerado eles representam percentuais absolutos de queda do ensino básico, respectivamente iguais a I,04\%, 0,97\% e 1,3\% para as séries escolares em questão. Deve-se ressaltar que esses porcentuais mostram que o déficit é pequeno, tendo em conta o tamanho da escala de avaliação, pouco significando para concluir que o ensino de Língua Portuguesa na educação básica seja um desastre irrecuperável. Mas é bom lembrar que em aprendizagem nenhum déficit é desejável, principalmente quando ele se apresenta de forma acumulada como no caso revelado pelo Saeb.

Da mesma forma, é possível visualizar pelo gráfico 2 como se comportaram as diferenças das médias em Matemática de uma edição para outra do Saeb. 
GRÁFICO 2

VARIAÇÃO DAS DIFERENÇAS ENTRE AS MÉDIAS DE PROFICIÊNCIA EM MATEMÁTICA NA SÉRIE HISTÓRIA DO SAEB ( $1995-2005)$

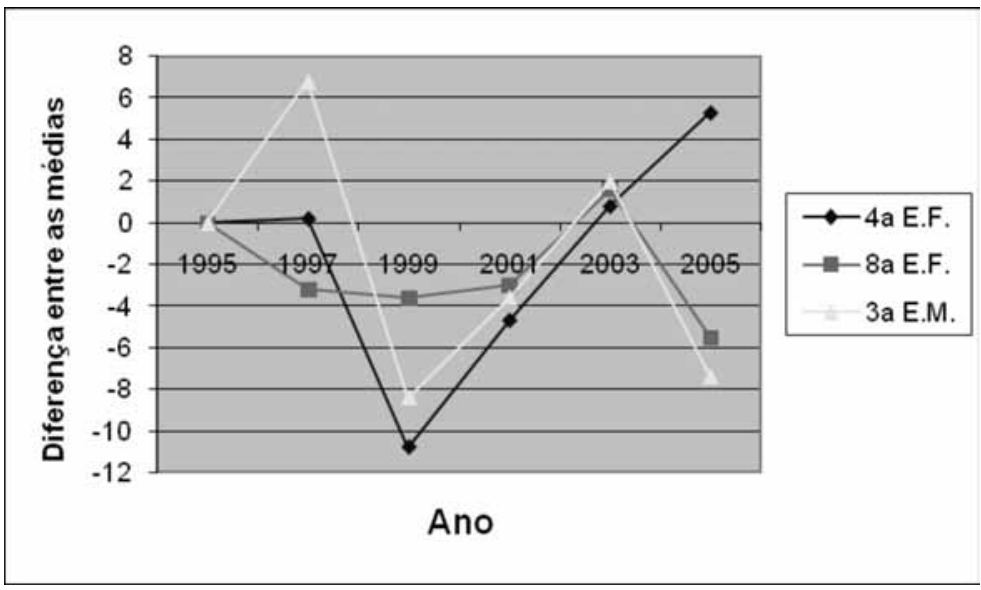

Fonte: Brasil (2007b, p. 7).

gráfico mostra que em Matemática as diferenças entre as médias de uma edição para outra da prova também não conseguiram sair, em sua maioria, do plano das ordenadas negativas. $\bigcirc$ valor médio de todas as diferenças nessa disciplina para a quarta série do ensino fundamental foi de - 1,84; para a oitava série foi de -2,74; e para a terceira série do nível médio foi de -2, I 2. Os percentuais absolutos do déficit de aprendizagem em relação à escala de 500 pontos utilizada nos testes foram respectivamente iguais a 0,37\%, 0,55\% e 0,42\% para cada uma dessas séries, reforçando a tese que os escores negativos constituem porcentuais pequenos para significarem a falência da Matemática no sistema de ensino. Mas não deixa de ser preocupante o fato de que, a exemplo de Língua Portuguesa, o déficit de aprendizagem dos alunos em Matemática também está se acumulando ano após ano.

planejamento e a operacionalização do Saeb são de competência do Instituto Nacional de Estudos e Pesquisas Educacionais Anísio Teixeira Inep -, que define os objetivos específicos de cada procedimento avaliativo, os instrumentos utilizados, as séries e disciplinas, bem como as competências e habilidades a serem avaliadas. Para o presidente do Inep em 2007, Reynaldo 
Fernandes, uma das explicações para a piora do rendimento da educação básica encontra-se no aumento do número de alunos no final da década de 1990, durante o governo Fernando Henrique Cardoso. "A queda no rendimento é um efeito da expansão do ensino, que também aconteceu nos anos 60 nos Estados Unidos" (2007, p. I). Essa explicação foi reiterada pelo então Ministro da Educação, Fernando Haddad, para quem, em relação aos resultados insatisfatórios dos alunos no Saeb, "temos de deixar claro que [...] houve a expansão do final dos anos 90" (2007, p. 2). Especialistas, como Artur Costa Neto, da Faculdade de Educação da Pontifícia Universidade Católica de São Paulo - PUC-SP -, citam como fatores que contribuíram para o fraco desempenho do Estado de São Paulo "uma errônea aplicação do sistema de progressão continuada, a falta de estrutura para absorver estudantes, a ausência de incentivo a professores e políticas públicas imediatistas" (2007, p. 3). Outros, como Franco (200 I , p. I28) admitem até mesmo que "é difícil oferecer, a partir dos dados do Saeb, explicações bem fundamentadas sobre os fatores escolares que influenciam o aprendizado dos alunos". Para esse autor, seria necessária uma dupla medida de proficiência para que os efeitos do contexto escolar na aprendizagem possam ser entendidos, apontando que ainda há muitas questões em aberto relacionadas com a amostra do Saeb e também que há a necessidade de aprimorar as medidas sobre as condicionantes escolares que influem na proficiência dos alunos.

Dessa forma, as dificuldades do Saeb em resolver os problemas inerentes ao modelo de avaliação adotado encontram ressonância na literatura produzida no Brasil sobre o tema. Barretto et al. (200I, p. 57) afirmam que "praticamente quase não foram encontradas análises que se aprofundem no exame dos pressupostos do modelo, o que denota uma insuficiência de interpretação na bibliografia". Dessa forma, é impreterível que os pressupostos teóricometodológicos do Saeb sejam analisados a fundo, bem como também é necessário que os responsáveis pelas políticas educacionais aprofundem a prestação de contas [accountability] sobre o mau desempenho até agora observado entre os estudantes.

\section{A PROGRESSÃO CONTINUADA E OS RESULTADOS DO SAEB}

A evasão e a reprovação escolares são fenômenos relacionados ao fato de as famílias de baixa renda não conseguirem manter os filhos na escola ou 
não propiciarem a esses as matrizes culturais extraescolares necessárias para o sucesso na aprendizagem. Surgem assim programas de compensação financeira para melhorar a sustentabilidade dessas famílias e com isso sustentarem os filhos estudando, bem como políticas de não repetência que demandam o regime de progressão continuada. Criado em 1996, esse regime foi adotado no ensino fundamental por boa parte das redes públicas, com a proposta de promover o aluno independentemente das notas dentro de ciclos plurianuais. Disso, emergiram indagações sobre se a experiência contribuiu para melhorar o desempenho dos alunos ou se, ao contrário, produziu queda no seu aproveitamento.

Ferrão, Beltrão e Santos utilizaram um modelo estatístico de regressão multinível para comparar os regimes de ensino seriado e com promoção automática nos estratos escolares, tomando como dados iniciais os resultados do Saeb-99:

Relativamente às escolas que constituem a [nossa] amostra, os modelos apresentados sugerem que, nos estados de São Paulo e Minas Gerais, o regime de promoção automática, pelo menos nas escolas públicas, pode contribuir para a correção da defasagem idade-série sem perda da qualidade na educação. Não foi encontrada evidência de que o desempenho acadêmico dos alunos com defasagem idade-série seja inferior ao desempenho dos alunos em idade adequada por causa do regime de organização do ensino em vigor na escola que ele frequenta. Também não foi encontrada evidência de que alunos desfavorecidos socioeconomicamente que estudam em escolas com promoção automática tenham desempenho inferior aos seus colegas. (2007, p. 23)

Os autores aventaram refazer o estudo com os dados do Saeb de 200 I, o que ainda não foi publicado, mas é revelador o fato por eles verificado de que o regime de promoção automática adotado pelas escolas públicas das redes focalizadas não contribuiu para a perda de qualidade em termos dos dados de 1999. Os ditos regimes, no entanto, concorreram para minorar os efeitos dos famigerados problemas da evasão e da defasagem idade-série ocasionados pela repetência.

Neves e Boruchovitch investigaram as orientações motivacionais intrínsecas e extrínsecas de alunos no contexto da progressão continuada e indicam que uma porcentagem expressiva de estudantes ignora completamente o sistema de promoção a que estão submetidos. Sua motivação para o estudo é predominantemente intrínseca, de forma que lhes importa saber se irão ou não repetir o ano: 
....acredita-se que um achado importante do presente estudo [feito com alunos em regime de progressão continuada] diz respeito ao fato de que eles se apresentaram motivados para estudar desde o início da escolaridade, reconhecendo, de modo geral, o valor da função social da escola e apresentando crenças positivas e favoráveis à aprendizagem. (2004, p. 83)

Não são os fatores extrínsecos que em essência motivam a aprendizagem, dizem as autoras, de forma que a repetência nada mais é do que um estigma para impor práticas autoritárias dentro da escola, ao contrário do que a pedagogia sempre acreditou.

Gomes (2005) faz um amplo levantamento da literatura produzida em outros países relativa à "desseriação escolar", nome usualmente dado aos regimes educacionais de não repetência. Diz o autor à página 12 do seu artigo que "a literatura internacional oferece um panorama pouco favorável à reprovação [...] como um fator de grande impacto positivo sobre o rendimento discente". $\mathrm{Na}$ maioria dos países onde a promoção automática é adotada, o aluno é cercado de cuidados especiais para melhorar a sua aprendizagem, o que tem gerado em certos casos elevação nos escores de avaliação, fazendo com que a reprovação perca sua condição pedagógica de impacto. A reprovação, conclui o autor, somente pode render resultados positivos quando os alunos retidos recebem atenção especial.

Jacomini analisou a implantação da progressão continuada e a organização do ensino fundamental em dois ciclos (ciclo I - os quatro primeiros anos; e ciclo 2 - os quatro últimos anos) na rede estadual paulista em 1998. Relata que houve fortes condicionantes de resistência dos professores, decorrentes, entre outros aspectos, da não diminuição necessária do número de alunos por classe, que em alguns casos até mesmo aumentou. Além disso, a conexão entre os dois ciclos era dificultada porque o sistema foi implantado de forma que os ciclos I e 2 não funcionavam na mesma escola. As condições salariais dos educadores naquela época, que se estendem até hoje, impediam que eles tivessem uma única jornada de trabalho e dessa forma pudessem dedicar-se adequadamente à atividade pedagógica, garantindo que fossem introduzidas metodologias de ensino necessárias para dar sustentabilidade aos ciclos de progressão continuada. Dessa forma, as políticas estabelecidas ao longo dos anos para a rede pública estadual paulista fizeram com que a reprovação se tornasse parte intrínseca 
do processo de ensino e os professores não se vissem em condições de rever essa concepção. Desse modo, "a não organização pedagógica e institucional da escola para funcionar em ciclos e adotar a não reprovação como princípio pedagógico reforçou os condicionantes ideológicos, criando uma forte resistência dos educadores paulistas à promoção continuada" (Jacomini, 2004, p. 4I5). Mesmo assim, o aspecto negativo das condições que os professores tiveram para implementar as mudanças pedagógicas decorrentes da adoção dos ciclos de não repetência, constitui uma hipótese sobre a qual não se pode ter certeza para explicar a acentuada queda revelada pelo Saeb a respeito da proficiência dos alunos no Estado de São Paulo.

O trabalho de Freitas (2002) articula-se à ideia de que a progressão continuada tem sido uma forma de o Estado minimizar os custos sociais da má qualidade da educação pública, no sentido de que o aluno permanece na escola mesmo sem aprendizagem, ao contrário de quando era puramente eliminado. Ao retirar das pessoas as chances de aprender, a repetência e a evasão geram custos sociais que oneram o Estado, de forma que elas sim é que precisam ser eliminadas, não o aluno. Não é a qualidade da escola que está em jogo, mas sim a otimização do fluxo de formação dos alunos, segundo princípios que visam a abaixar o volume de gastos de um Estado obediente aos pressupostos neoliberais da economia. Ao implantar a progressão continuada sem modificar a infraestrutura da escola, o Estado deixa de cumprir com sua responsabilidade por mais investimentos diretos na educação, estabelecendo políticas públicas paliativas, entre as quais se destacam o próprio Saeb.

Conclui-se pela análise da literatura que não há indícios seguros dos maus resultados verificados pelo Saeb serem uma consequência direta da adoção da progressão continuada, mesmo diante das condições adversas em que ela foi implantada no Brasil. Como se constata, muitos autores chegam a rechaçar completamente a ideia de que haja alguma relação direta entre as políticas de não repetência e o aproveitamento dos alunos.

\section{EXPANSÃO DAS MATRÍCULAS E QUALIDADE DO ENSINO FUNDAMENTAL}

A relação de dependência entre a expansão das matrículas e a queda de qualidade nos sistemas de ensino é aceita quase por unanimidade como uma verdade sedimentada que apresenta poucas refutações. A universalização do 
ensino fundamental no Brasil, que produziu um grande aumento no contingente de matriculados, teria por sua vez produzido uma queda na proficiência dos alunos, pois esses passaram a competir em maior número pelos recursos do Estado. Colocam-se nessa categoria de análise os trabalhos de Ferrão, Beltrão e Santos (2007), Neves e Boruchovitch (2004), Gomes (2005) e Jacomini (2004). Para Oliveira e Araújo, "[no] processo de expansão das oportunidades a escola incorporou as tensões, as contradições e as diferenças presentes na sociedade" (2005, p. 8). Mesmo especialistas nacionais anteriores à atual época de incidência dos processos avaliativos, como Beisiegel (1964) e (Mello, 1979), respaldam o discurso de que a educação do passado parecia ser de melhor qualidade. Segundo Gentili (1997), Macedo (2006) e Freitas (2002, 2004), o problema está em que hoje o conceito de qualidade em educação é formado por uma falsa visão, que decorre de interpretações indevidas das teorias econômicas neoliberais de produtividade industrial. Em respaldo à ideia desses últimos autores, considere-se o gráfico 3, que apresenta a evolução absoluta das matrículas no ensino fundamental no Brasil desde a década de 1980 até a atual.

GRÁFICO 3

EVOLUÇÃO DAS MATRÍCULAS NO ENSINO FUNDAMENTAL BRASIL (I980- 2002)

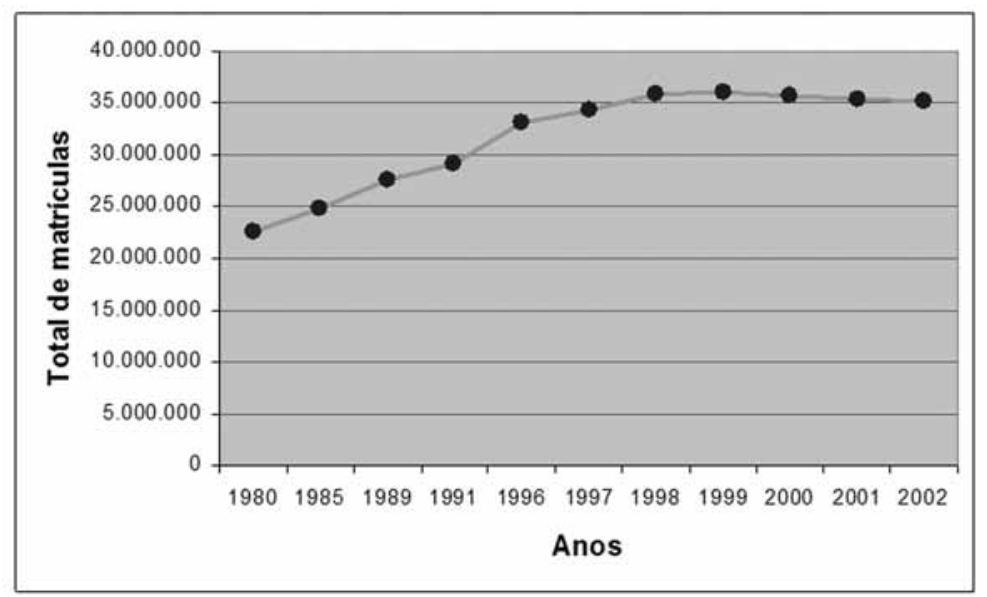

Fonte: Oliveira, Araújo (2005, p. 9).

crescimento absoluto das matrículas demonstra que o sistema se expandiu em quase $80 \%$ no período considerado. Acredita-se que os escores sofríveis mostrados pelo Saeb sejam uma consequência de tal expansão, mas 
esse é um exercício puramente ficcional, sendo impossível saber se os alunos do passado teriam melhor proficiência nas provas de um hipotético Saeb. Para evitar incongruências e exprimir quantitativamente o significado social da expansão, é preciso levar em conta a Taxa de Escolarização Bruta - TEB - do ensino fundamental. Esse indicador, calculado por meio da relação entre o número anual de matrículas e a população total censitária que se encontra na faixa etária dos sete aos quatorze anos, não depende da idade dos alunos matriculados, mas apenas do número que representa a sua quantidade. A faixa etária da população teoricamente adequada para o ensino fundamental é dos 7 aos 14 anos, mas tendo em vista que no Brasil somente na década de 1990 as distorções causadas pelos elevados índices de repetência e evasão começaram a ser corrigidos, até hoje uma parcela dos alunos matriculados está acima da idade máxima. O gráfico 4 mostra a evolução da TEB do ensino fundamental desde a década de 1980 até o ano 2002. Os valores calculados excedem aos 100\%, máximo que seria atingido se as matrículas se restringissem à população com idade adequada para esse nível de ensino.

\section{GRÁFICO 4}

TAXA DE ESCOLARIZAÇÃO BRUTA DO ENSINO FUNDAMENTAL BRASIL (1980- 2002)

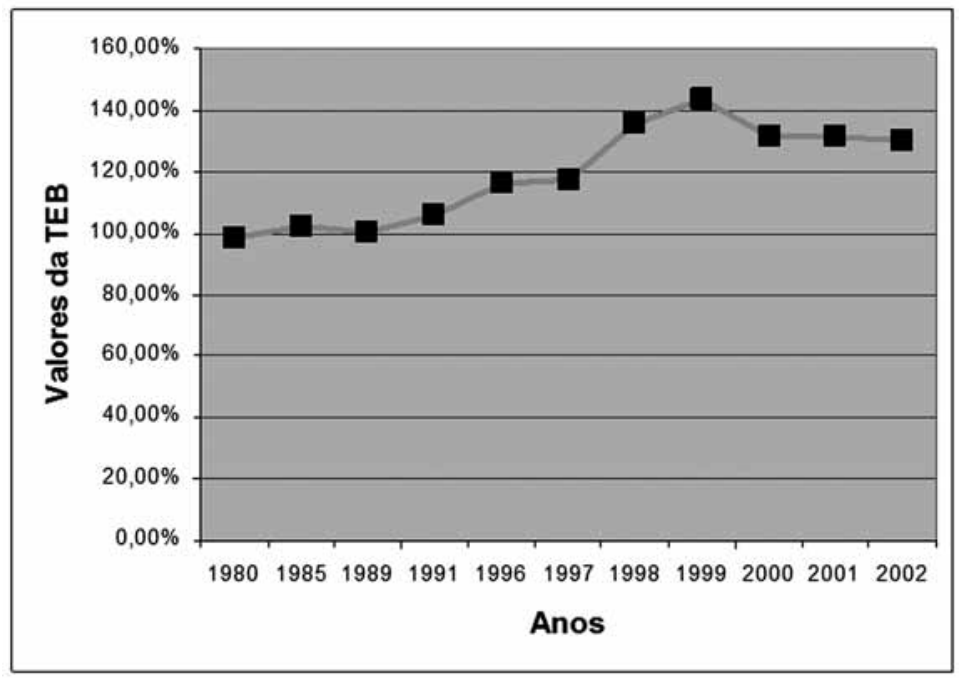

Fonte: Oliveira, Araújo (2005, p. 9). 
A linha de evolução da TEB é caracterizada por altos e baixos que não se verificam no plano das matrículas, obedecendo às variantes do crescimento populacional. Enquanto a variação máxima das matrículas no período chegou próxima à casa dos $80 \%$, a da TEB atingiu pouco mais de $40 \%$. Isso minimiza os efeitos negativos do aumento das matrículas na qualidade das notas, uma vez que a expansão dos indicadores sociais foi muito maior. Os resultados do Saeb devem ser associados a indicadores de natureza social mais amplos, como a TEB e não simplesmente ao conceito de qualidade das notas, que pouca contribuição traz para a formulação de políticas públicas. Mesmo assim, a TEB ainda não representa o indicador definitivo para exprimir a melhoria do ensino fundamental no sentido social. Para isso, é preciso realizar o produto da TEB pelas respectivas médias de proficiência nos exames do Saeb. O gráfico 5 mostra a variação desse produto em alguns anos selecionados, tendo em conta as médias de proficiência em Português dos alunos da $8^{a}$ série dentro da escala padrão de 500 pontos e a expressão da TEB em termos dos valores decimais correspondentes às porcentagens.

\section{GRÁFICO 5}

QUALIDADE SOCIAL DO ENSINO FUNDAMENTAL MEDIDA PELO PRODUTO DA TEB COM A MÉDIA DE PROFICIÊNCIA EM PORTUGUÊS OBTIDA NO SAEB PELOS ALUNOS DA \& SÉRIE BRASIL (ANOS SELECIONADOS)

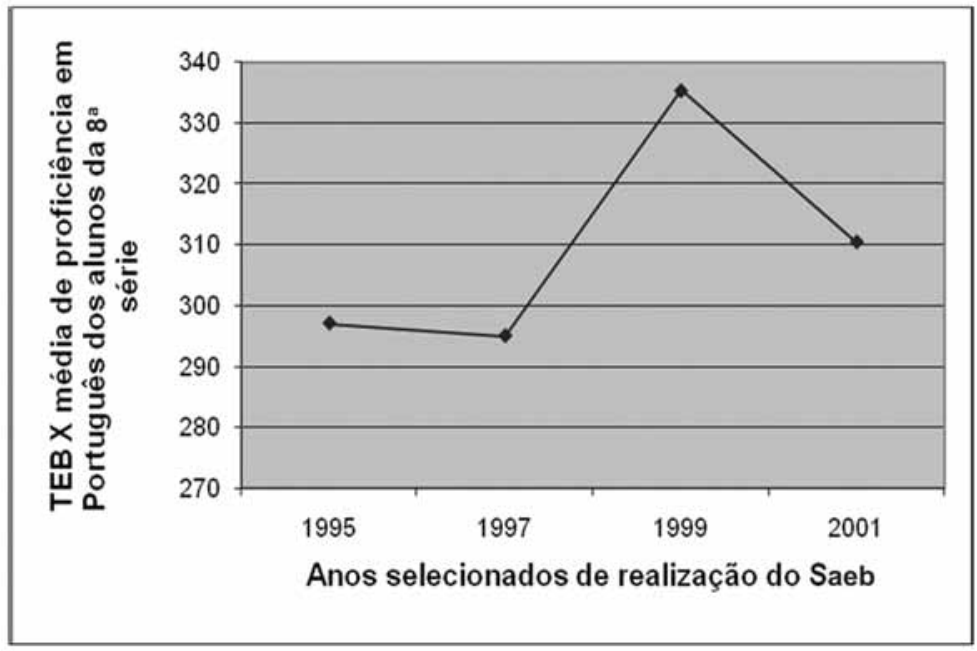

Fonte: Brasil (2007b, p. 7); Oliveira, Araújo (2005, p. 9). 
Os índices apresentados no gráfico 5 equilibram os possíveis efeitos negativos que a variação da TEB pode ter sobre a qualidade de ensino, constituindo uma forma de raciocinar que dificulta interpretações subjetivas em relação ao comportamento do sistema educacional. Quando a TEB aumenta e a média das notas pretensamente cai, ou quando a TEB diminui e se supõe que essa média aumentará, o índice determinado pelo produto numérico oferece uma norma de regulação que diminui expectativas de análises tendenciosas. Se os aspectos qualitativos que constituem o indicador representam de fato uma forma coerente de abordar a qualidade da educação em seu sentido social, um dado interessante é que os índices não diminuíram no período considerado, mas pelo contrário, seus valores aumentaram.

Há vários argumentos que podem ser invocados a favor da análise de qualidade proposta no gráfico 5, que relaciona a TEB com as notas do Saeb. Em primeiro lugar, a TEB é um dos valores que entram na composição da dimensão educacional do Índice de Desenvolvimento Humano - IDH -, "medida pela taxa de alfabetização de adultos e pela taxa de escolarização bruta combinada dos ensinos primário, secundário e superior" (Biblioteca Virtual de Direitos Humanos, 2005, p. I). Dessa forma, há razões de sobra para utilizar a TEB no cotejamento da qualidade de ensino, que multiplicada pelas notas do Saeb garante que seja estabelecido um sentido sociológico para essas notas. Além disso, as relações transversais entre as variáveis que fazem a qualidade da aprendizagem variar ano a ano precisam ser consideradas quando se pretende analisar os resultados do Saeb. Mesmo que a comparabilidade longitudinal das notas seja garantida, os fatores transversais necessários para exprimir as circunstâncias sociais em que tais notas foram produzidas têm sido desconsiderados até agora. Entre esses fatores, a TEB sem dúvida deve ser destacada, pois sua importância no cálculo do IDH Ihe dá um papel central no que toca ao planejamento das políticas sociais. Assim, o indicador utilizado no gráfico 5, entre outros que valorizam a dimensão sociológica da avaliação, deveria estar presente no documento de divulgação da série histórica do Saeb (Brasil, 2007b), pois a apresentação apenas das notas de proficiência dos alunos nesse relatório como resultado final tem provocado muitas distorções analíticas, típicas do tecnicismo econômico neoliberal aplicado à educação, aqui já apontado.

No Brasil, causa bastante mal-estar admitir que os índices da educação só estejam caindo, enquanto a expansão média anual do Produto Interno 
Bruto - PIB -, de 1997 a 2006, foi de 2,2\% e o PIB per capita cresceu 0,7\%. Ao analisar a evolução dos investimentos em educação pública no Brasil na década passada, Ribeiro (200I) informa que o valor médio per capita foi de $\mathrm{R} \$$ 79,63 no período 1993-1999, tomando a população total do país como denominador, e não somente o número de beneficiários das políticas de educação. A taxa média de crescimento desse indicador naquele período foi de 2,96\%. Assim, os dados sobre os investimentos na educação pública na década de 90 "mostram que essa área da política social brasileira conseguiu manter intacta a espinha dorsal de sua estrutura de financiamento - vinculação de impostos e contribuições sociais" (Castro, 200 I, p. 29). Para o financiamento específico do ensino fundamental, foi concebido um instrumento político capaz de induzir transformações onde estão de fato os alunos e professores, na totalidade das redes de ensino. Trata-se do Fundo de Manutenção e Desenvolvimento do ensino fundamental e de Valorização do Magistério - Fundef -, que produziu uma realocação de recursos de tal forma a promover o aumento de matrículas, tornando o país próximo de conseguir colocar todas as crianças na escola desde o final da última década. Além disso, o Fundef permitiu ampliar significativamente os montantes destinados a financiar a capacitação e habilitação de professores, produzindo melhorias salariais. Destaca-se ainda o aumento no valor de gastos com a construção, ampliação, reforma e manutenção de escolas, bem como com equipamentos, material e transporte escolar. No entanto, mesmo com o Fundef "é inegável que os indicadores de qualidade do ensino público, quando consultados, ainda reiteram uma situação que está muito aquém do razoável" (Semeghini, 200l, p. 56).

Em geral, os indicadores utilizados para avaliar a qualidade do ensino no Brasil carecem de maior poder de síntese, pois deixam de englobar as variáveis sociais das quais dependem o funcionamento das unidades escolares e das redes de educação entendidas como macrossistemas. $O$ indicador aqui sugerido, que associa as notas do Saeb com a TEB, aproxima-se da síntese necessária, uma vez que, com base nas notas, considera a inclusão social representada pelo aumento do número de matrículas. A perspectiva fornecida pelo indicador contribui para aperfeiçoar a esfera de planejamento das políticas públicas educacionais, interpretando o sistema de ensino por meio da associação de outras variações que não apenas o resultado das provas de avaliação da aprendizagem. 


\section{O NOVO ÍNDICE OFICIAL DA EDUCAÇÃO BÁSICA}

Em I 5 de março de 2007, é divulgada uma política de governo denominada Plano de Desenvolvimento da Educação - PDE - que, pela primeira vez no Brasil, envolve em um mesmo eixo diretor a educação básica, superior, profissional e continuada. O PDE surge num momento em que a educação brasileira, sob o impacto da divulgação da série histórica do Saeb do período 1995-2005, é considerada uma das piores do mundo, ressaltando a necessidade de que uma ação conjunta das esferas municipais, estaduais e federal seja empreendida para enfrentar os problemas. $\bigcirc$ foco da visão sistêmica pretendida pelo PDE para a educação básica contempla a melhoria da qualidade por meio do aumento nos investimentos e aperfeiçoamento da gestão de recursos pelos agentes públicos responsáveis. Entre as medidas adotadas, está a criação do Índice de Desenvolvimento da Educação Básica - Ideb -, decorrente de uma nova geração de indicadores para avaliar a qualidade de ensino no país. A nova concepção de cálculo de qualidade representado pelo ldeb combina o desempenho da aprendizagem com o fluxo escolar, atribuindo notas de zero a dez a cada município. Com base nessa nota, está prevista a distribuição de recursos adicionais para os municípios com os escores de qualidade mais baixos, tendo em conta o Fundo de Manutenção e Desenvolvimento da Educação Básica e de Valorização dos Profissionais da Educação - Fundeb. A princípio, tanto nesse último sistema quanto no anterior, o Fundef, a estratégia básica é disponibilizar um valor anual mínimo por matrícula a cada rede educacional existente no país. As análises revelam que:

Embora os fundos tragam quase nenhuma (Fundef) ou pouca (Fundeb) receita nova para o conjunto nacional das redes estaduais e municipais da educação básica, muitos governos terão ganhos expressivos, porém muitos outros terão perdas significativas, porque esta é a lógica desses fundos, baseada na redistribuição de acordo com o número de matrículas. [...]. Cabe ressaltar que, embora a lógica do Fundef e do Fundeb seja aparentemente democrática ao promover um nivelamento de recursos por matrícula dentro de cada estado e, portanto, uma diminuição da desigualdade entre a rede estadual e as redes municipais de cada estado, no caso do Fundef ela provocou perdas significativas em mais de 2.000 municípios pobres e é provável que o mesmo ocorra no Fundeb, pois a lógica é a mesma. (Davies, 2006, p. 770) 
O PDE surge como uma proposta para tentar corrigir as distorções existentes, atrelando a complementação das verbas do Fundeb para cada município ao novo indicador que está sendo engendrado. Os municípios que apresentarem os piores índices receberão mais investimentos por aluno, e isso representa um avanço nas políticas públicas de distribuição dos recursos para a educação no Brasil, pois aproxima essas políticas de uma desejável paridade equitativa baseada na consideração das realidades sociais locais que inibem o desenvolvimento das redes educacionais. A distribuição de recursos para as redes de educação segundo a proporção de matrículas é simples de administrar, o que provavelmente levou o país a adotá-lo como único critério até o presente momento. Tendo em conta novas perspectivas que serão abertas pelo cálculo do Ideb, é possível pensar até mesmo que o Fundeb passe a utilizá-lo no futuro como norma geral para a distribuição de recursos, e não somente no que toca às complementações necessárias. Para entender as bases lógicas de como o Ideb pode ser calculado, há as teorias da correção do fluxo escolar de Carvalho (200 I), o artigo de Goulart, Sampaio e Nespoli (2006), que contém a tabela completa das taxas de transição por série da Educação Básica brasileira de 1995 a 2003. Há, também, o trabalho amplamente citado de (Klein, 2003).

Com relação às metas educacionais, o MEC anunciou que "o índice do país vai ser fixado em seis, média que os países da Organização para a Cooperação e Desenvolvimento Econômico - OCDE - teriam nessa escala" (Brasil, 2007). Essa afirmação, feita pelo ministro da educação, Fernando Haddad, após uma audiência pública na Câmara dos Deputados no dia 27 de março de 2007. é ambígua no que diz respeito à formulação do Ideb, pois o cálculo da OCDE leva em consideração os resultados do Pisa, cuja metodologia é diversa da do Saeb. Para o Ideb ser calculado como informou o ministro, haveria necessidade de implantar uma nova prova nacional específica para ser aplicada aos jovens de 15 anos de idade em todos os municípios, com o objetivo de avaliar o conhecimento em matemática e ciências, bem como as habilidades de leitura, pois esse é o modelo do Pisa. Para utilizar os próprios resultados do Pisa sem a necessidade do Brasil desenvolver novas e caras metodologias de avaliação, o máximo que se conseguirá medir serão os resultados específicos das cinco grandes regiões brasileiras, unidade geopolítica mínima em que são computadas as amostras daquele exame. A metodologia do Pisa não permite que se possa ter uma classificação dos resultados em termos dos municípios, mas o Ideb 
precisa disso para efeito de o país conseguir formular suas políticas públicas, tradicionalmente concebidas em termos das suas unidades administrativas municipais. Dessa forma, a falta de uma infraestrutura avaliativa para o Brasil adotar um indicador que exprima a qualidade da educação básica comparativamente àquela computada pela $\mathrm{OCDE}$, torna pouco precisa a meta anunciada pelo então ministro da educação. O MEC poderia ter fixado a média 6 como meta do Brasil no Pisa, mas no caso do Ideb esse valor é destituído de sentido, uma vez que é calculado com base em médias obtidas pelos municípios no Saeb, uma outra realidade de exame. A média em Matemática obtida pelos alunos da 8 a série em 2005 foi de 240 pontos, que convertida para a escala de 10 pontos resulta em 4,8. Esse valor não está distante da média 6 proposta pelo MEC. Parece que há um engano fundamental quanto à formulação de políticas públicas pelo MEC, pois a metodologia do Pisa e consequentemente a expressão de suas notas são outras que não as do Saeb, de forma que os dois sistemas não podem ser comparados. Se assim não fosse, em matemática os alunos do $3^{\circ}$ ano do ensino médio já estariam a poucos décimos da meta, pois obtiveram média igual a 5,42 nessa disciplina em 2005.

A composição do Ideb inclui também a medida do fluxo escolar, que leva em conta a relação entre o número de alunos que foram considerados aprovados e o total dos que fizeram matrícula. Define-se a matrícula total na série $k$ no ano t como o número obtido pela soma de todos os alunos admitidos no sistema para cursar o ano letivo. Para um sistema fechado, isto é, quando se supõe que todos os alunos computados na matrícula inicial do ano $t$ permaneceram na escola, não havendo transferências para dentro e para fora, nem evasão, o fluxo escolar do ano em pauta é calculado pela relação entre a soma de todos os alunos da série $k$, promovidos para a série $k+1$, incluindo os que se formaram.

Não sendo recomendável que as compensações financeiras funcionem como políticas de valorização do desempenho, o benefício aos municípios brasileiros que apresentarem o pior Ideb não poderá ser distribuído de acordo com o simples critério da proporcionalidade de matrículas, nem de dotar os mais fracos com uma quantidade maior de recursos, devendo sim os primeiros entre os mais fracos receberem proporcionalmente mais. Isso minimiza os efeitos nocivos da cultura de compensação dos mais fracos, pois impõe que vale a pena ser relativamente forte entre eles. Uma filosofia dessa natureza garantirá pelo menos que o pressuposto da competitividade, tão caro ao pen- 
samento neoliberal, de alguma forma esteja na implantação do PDE. Conforme apregoam as doutrinas neoliberais, a utilização de indicadores de desempenho não é eficiente para planejar a melhoria dos sistemas econômicos sem que a competitividade própria da noção de mercado esteja em algum nível presente. O planejamento dos sistemas educacionais tem passado definitivamente pela ótica econômica dentro das políticas públicas contemporâneas, mas os indicadores de avaliação da educação básica precisam ir além disso, para que de fato se produza melhoria na qualidade de ensino.

\section{CONCLUSÕES}

A influência das teorias econômicas neoliberais consolidou-se no campo educacional pela avaliação da qualidade por meio de provas aplicadas para medir o desempenho dos estudantes e pela realização de experiências políticos-organizacionais voltadas para a melhoria do funcionamento das unidades escolares, visando abranger o sistema de ensino em sua totalidade. No entanto, é visível que a cultura da avaliação em educação baseada em pressupostos puramente economicistas é pífia. Foi produzida contemporaneamente uma vasta literatura crítica que se opõe frontalmente ao discurso do desenvolvimentismo educacional na pauta dos interesses financeiros dos formadores oportunistas de opinião e formuladores de políticas públicas ambíguas.

No âmbito da legislação política e da literatura de apoio técnico criadas respectivamente para regular e subsidiar os processos de avaliação, surge a questão dos indicadores de qualidade como um ponto fundamental. Essa questão se torna ainda mais crucial quando o Saeb, sistema brasileiro formulado para avaliar a escola e os alunos, mostra que durante a década de 1995 a 2005 houve um acúmulo crescente de déficits de aprendizagem. Normalmente, tais déficits são utilizados para inferir que a educação básica fracassou, mas é necessário interpretar os resultados de forma que eles agreguem também os ganhos sociais decorrentes da aplicação de políticas públicas inclusivas, como é o caso da não-repetência, que conseguiu corrigir as graves distorções do fluxo escolar. Associando-se as médias dos alunos com as taxas brutas de matrícula, verifica-se que o sistema apresenta ganhos dentro de um contexto em que essa forma de abordar a qualidade da educação tem amplo sentido social. Quando a taxa bruta aumenta, o rendimento escolar tende a cair e 
vice-versa, de forma que no Brasil esse equilíbrio mostrou variação positiva, ou seja, a inclusão escolar não é a responsável direta pelo aumento dos déficits de aprendizagem observados.

Se forem mal interpretados, os déficits de aprendizagem acumulados pelos alunos da educação básica brasileira poderão estimular o reaparecimento das políticas de repetência como proposta para melhorar a qualidade do ensino, perdendo-se as conquistas sociais representadas pela universalização das matrículas, tão duramente conseguidas. Pode-se dizer que é melhor um aluno estar matriculado em uma escola de má qualidade do que ficar fora dela. Isso não significa que a busca pela melhoria da qualidade deixe de ser perseguida, porém é preciso encontrar formas de fazê-lo sem excluir os alunos.

O Plano de Desenvolvimento de Educação apresentado pelo MEC em 2007 representa um caminho para promover a desejada melhoria da qualidade na escola sem expurgos sociais, mas isso só foi possível porque seu principal indicador, o ldeb, incorporou definitivamente a ideia de que a inclusão escolar é uma política que não pode ser abandonada.

\section{REFERÊNCIAS BIBLIOGRÁFICAS}

BARRETTO, E. S. S. et al. Avaliação na educação básica nos anos 90 segundo os periódicos acadêmicos. Cadernos de Pesquisa, n. I14, p. 49-88, nov. 2001.

BEISIEGEL, C. R. Ação política e expansão da rede escolar. Pesquisa e Educação, São Paulo, n. I, p. 5-23, 1964.

BIBLIOTECA VIRTUAL DE DIREITOS HUMANOS. Sobre o Índice de Desenvolvimento Humano. 2005. Disponível em: <http://72. 1 4.209. I 04/search?q=cache:kEODHU4jb3Ej:www.direitoshumanos.usp.br/counter/Onu/Desenvolvimento/texto/sobrepnude.htm + taxa + escola riza\%C3\%A7\%C3\%A3o+ONU\&hl=pt-BR\&ct=clnk\&cd=2>. Acesso em: 28 fev.2007.

BOURDIEU, P. A Economia das trocas simbólicas. 5. ed. São Paulo: Perspectiva, 2003.

BRASIL. Decreto n. 2.026, de 10 de outubro de 1996. Estabelece procedimentos para o processo de avaliação dos cursos e instituições do ensino superior. DOU, Braślia, seção I, p. 20546, II out. 1996.

. Decreto n. 3.860, de 9 de julho de 200 I. Dispõe sobre a organização do ensino superior, a avaliação de cursos e instituições, e dá outras providências. $200 \mathrm{I}$. Disponível em: <http://www.ead.ufsc.br/profor/disciplinas/textos/texto008.pdf>. Acesso em: I2 out. 2004. 
. Lei n. 10.86I, de 14 de abril de 2004. Institui o Sistema Nacional da Avaliação Superior e dá outras providências. 2004. Disponível em: < http://www.mec.gov.br/legis/ pdf/I086।.pdf>. Acesso em: 17 dez. 2004.

. Portaria n. 2.05I, de 9 de julho de 2004a. Regulamenta os procedimentos de avaliação do Sistema Nacional de Avaliação da Educação Superior, instituído na lei 10.861 , de 14 de abril de 2004. DOU, Brasília, seção I, n. I32, p. I2, 10 jul. 2004a.

. Portaria n. 931, de 21 de março de 2005: institui o Sistema de Avaliação da Educação Básica. DOU, Brasília, seção I, 22 mar. 2005.

BRASIL. Ministério da Educação. Sinaes. Orientações gerais para o roteiro da autoavaliação das instituições. Brasília, 2004b.

. Índice de qualidade da educação. Brasília: 2007. Disponível em: < http://portal.mec. gov.br/index . php?option $=$ content\&task $=$ view\&id $=6687 \&$ FlagNoticias $=\mid$ \&ltemid $=6837>$. Acesso: 27 mar. 2007.

. Inep. Avaliação externa das instituições de ensino superior: diretrizes e instrumento. Brasília, 2005a.

. Inep. Sinopses estatísticas da educação básica (|99|-2006). Brasília, 2007a. Disponível em: <http://www.inep.gov.br/basica/censo/Escolar/Sinopse/sinopse.asp > . Acesso: 18 fev. 2007a.

. Saeb - 2005 primeiros resultados: médias de desempenho do Saeb/2005 em perspectiva comparada. Brasilia: Inep, 2007b.

. Secretaria do Ensino Superior. Uma nova política para a Educação Superior. Brasilia, 1985. Brasília, 2003.

. Sinaes. Bases para uma nova proposta de avaliação da educação superior.

CARVALHO, M. P. Estatísticas do desempenho escolar: o lado avesso. Educação e Sociedade, Campinas, v. 22, n. 77, p. 231 -252, dez. 2001.

CASTRO, J. A. Financiamento da educação no Brasil. Em Aberto, Brasília, v. 18, n. 74, p. II-32, dez. 2001.

COSTA NETO, A. SP tem a queda mais acentuada no país nas notas do Saeb. Folha de $S$. Paulo, São Paulo, Folha online, 8 fev. 2007. (entrevista a Fábio Takahashi; Antônio Gois; Jorge Soufen Jr.) Disponível em: <http://wwwl.folha.uol.com.brlfolhaleducaçãolult305ul9345. shtml >. Acesso em: 9 maio 2010.

DAVIES, N. Fundeb: a redenção da educação básica? Educação e Sociedade, Campinas, v. 27, n. 96, p.753-774, out. 2006. (Edição especial) 
DIAS, C. L.; MARCHELLI, P. S.; HORIGUELA, M. L. M. Políticas para avaliação da qualidade do ensino superior no Brasil: um balanço crítico. Educação e Pesquisa. São Paulo, v. 32, n. 3, p. 435-464, set./dez. 2006.

DIAS SOBRINHO, J. Avaliação: políticas educacionais e reformas da educação superior. São Paulo: Cortez, 2003.

. Universidade e avaliação: entre a ética e o mercado. Florianópolis: Insular, 2002.

. A Avaliação da educação superior. Petrópolis: Vozes, 2000.

FERNANDES, R. Aluno do ensino médio tem o pior desempenho em dez anos. Folha de S. Paulo, São Paulo, Folha online, 8 fev. 2007. (entrevista a Felipe Seligman) Disponível em:<http://wwwl.folha.uol.com.brlfolhaleducaçãolult305ul9343.shtml. Acesso em: 9 maio 2010.

FERRÃO, M. E.; BELTRÃO, K. I.; SANTOS, D. P. Política de não-repetência e a qualidade da educação: evidências obtidas da modelagem dos dados da $4^{a}$ série do Saeb-99. 2007. Disponível em: <http://www.mat.ubi.pt/ meferrao/qualidade.pdf>. Acesso em: 10. fev. 2007.

FRANCO, C. O Saeb - Sistema de Avaliação da educação básica: potencialidades, problemas e desafios. Revista Brasileira de Educação, Campinas, n. 17, p. I27-133, maio/ago. 2001.

FREITAS, L. C. A Internalização da exclusão. Educação e Sociedade, Campinas, v. 23, n. 80, p.299-325, set. 2002.

- A Avaliação e as reformas dos anos de 1990: novas formas de exclusão, velhas formas de subordinação. Educação e Sociedade, Campinas, v. 25, n. 86, p. 131-170, abr. 2004.

GENTILI, P. A. A. O Discurso da "qualidade" como nova retórica conservadora no campo educacional. In: GENTILI, P. A. A.; SILVA, T. T. (Org.). Neoliberalismo, qualidade total e educação: visões críticas. 5.ed. Petrópolis: Vozes, 1997. p. I I I- 177.

GOMES, A. M. Política de avaliação da educação superior: controle e massificação. Educação e Sociedade, Campinas, v. 23, n. 80, p. 275-298, set. 2002.

GOMES, C. A. Desseriação escolar: alternativa para o sucesso? Ensaio: Avaliação e Políticas Públicas em Educação, Rio de Janeiro, v. I3, n. 46, p. I I-38, jan./mar. 2005.

GONÇALVES FILHO, F. Enfoques avaliativos em revista: concepções de avaliação institucional em questão. Política da educação superior: GT I I. Brasília: FE/Unicamp, Capes, 2004. Disponível em: <http://www.anped.org.br/25/posteres/franciscogoncalvesfilhop I I.rtf>. Acesso em: 4 set. 2004. 
GOULART, L. T.; SAMPAIO, C. E. M.; NESPOLI, V. O Desafio de universalização do ensino médio. Brasília: Inep, 2006. Disponível em: <http://www.inep.gov.br/imprensa/artigos/2006/ universalizacao.htm>. Acesso em: 18 mar. 2007.

HADDAD, F. Ministro promete novo plano em um mês. Folha de S. Paulo, São Paulo, Folha online, 8 fev. 2007. (entrevista) Disponível em: <http://wwwl.folha.uol.com.br/folha/educação/ult305ul9344.shtml>. Acesso em: 9 maio 2010.

JACOMINI, M. A. A Escola e os educadores em tempo de ciclos e progressão continuada: uma análise das experiências no estado de São Paulo. Educação e Pesquisa, São Paulo, v. 30, n 3, p. $401-418$, set./dez. 2004.

KLEIN, R. Produção e utilização de indicadores educacionais: metodologia de cálculo dos indicadores do fluxo escolar da educação básica. Revista Brasileira de Estudos Pedagógicos, Brasília, v. 84, n. 206/207/208, p. 107- I57, jan./dez. 2003.

MACEDO, E. F. Novas tecnologias e currículo. In: MOREIRA, A. F. B. (Org.). Currículo: questões atuais. 12.ed. Campinas: Papirus, 2006. p. 39-58.

MELLO, G. N. Fatores intraescolares como mecanismo de seletividade no ensino de $1^{\circ}$. grau. Educação e Sociedade, Campinas, v. I, n. 2, p. 70-78. jan. 1979.

MOREIRA, C. O.; HORTALE, V. A.; HARTZ, Z. A. Avaliação da pós-graduação: buscando consenso. Revista Brasileira de Pós-Graduação, Brasília, v. I , n. I, p. 26-40, jul. 2004.

NEVES, E. R. C.; BORUCHOVITCH, E. A Motivação de alunos no contexto da progressão continuada. Psicologia: Teoria e Pesquisa, Brasília, v. 20, n. I, p. 77-85, jan./abr. 2004.

OLIVEIRA, R. P.; ARAÚJO, G. C. Qualidade do ensino: uma nova dimensão da luta pelo direito à educação. Revista Brasileira de Educação, Brasília, n. 28, jan. /abr. 2005.

RIBEIRO, J. A. C. Financiamento e gasto do Ministério da Educação nos anos 90. Em Aberto, Brasília, v. 18, n. 74, p. 33-42, dez. 2001.

RISTOFF, D. I.; DAVOK, D. F. Mudanças e resistências na construção da cultura da avaliação institucional. Revista Avaliação, Campinas, v. 5, n. 3, p. 27-36, 2000.

SEMEGHINI, U. C. Fundef: corrigindo distorções históricas. Em Aberto, Brasília, v. I8, n. 74, p. 43-57, dez. 2001 .

VIANNA, H. M. Novos estudos em avaliação educacional. Estudos em Avaliação Educacional, São Paulo, n. 19, p. 77-169, 1999.

Recebido em: abril 2007

Aprovado para publicação em: agosto 2009 